\title{
Characterisation of Borrelia burgdorferi sensu lato strains isolated from patients with skin manifestations of Lyme borreliosis residing in Slovenia
}

\author{
E. RUŽIĆ-SABLJ IĆ, F. STRLE*, J. CIMPERMAN*, V. MARASPIN*, S. LOTRIČ-FURLAN* and \\ D. PLETERSKI-RIGLER*
}

Institute of Microbiology and Immunology, Medical Faculty Ljubljana and *Department of Infectious Diseases, University Medical Centre Ljubljana, Slovenia

\begin{abstract}
Lyme borreliosis is the most prevalent tick-borne infection in Slovenia. Skin disorders are the most frequent clinical manifestations. The aim of the present study was to assess the phenotypic and genotypic diversity of a large number of human Borrelia burgdorferi sensu lato isolates and to evaluate any association between the isolates and different clinical manifestations. All 103 strains tested were from patients suffering from the skin disorders of Lyme borreliosis. Skin biopsies, cerebrospinal fluid and blood samples from patients were inoculated into modified Kelly Pettenkofer medium. Protein profiles were determined by SDS-PAGE and species identification and plasmid profiles by pulsed-field gel electrophoresis. Mlul digestion profiles showed that $87(84.5 \%)$ isolates belonged to B. afzelii, $15(14.5 \%)$ to B. garinii and $1(1 \%)$ to B. burgdorferi sensu stricto. The number of plasmids in each strain varied from three to seven, and the plasmid size ranged from 15 to $65 \mathrm{~kb}$. Four isolates of $\mathrm{B}$. garinii possessed multiple large plasmids and four isolates had a large plasmid dimer (three B. afzelii and one B. garinii). I solates showed qualitative and quantitative differences in protein expression. The study found differences in the expression of $\mathrm{OspB}$ and $\mathrm{OspC}$ proteins between $\mathrm{B}$. afzelii and $\mathrm{B}$. garinii strains. OspB was expressed significantly more often by B. afzelii (78 of 87 , $89.6 \%$ ) than by $\mathrm{B}$. garinii (4 of $15,26.6 \%$ ) isolates, while $0 \mathrm{spC}$ protein was expressed significantly more often by $B$. garinii ( 14 of $15,93.3 \%$ ) than by $B$. afzelii ( 51 of 87 , $58.6 \%$ ) isolates. In Slovenia, B. afzelii causes the majority of skin lesions. The isolates investigated showed plasmid and protein diversity. Heterogeneity of the spirochaetes may be important for virulence, and may have implications for pathogenesis and therapy of the infection. Differences in immunodominant proteins also have an important impact on serological testing and vaccine development.
\end{abstract}

\section{Introduction}

Lyme borreliosis is a multisystem disease that affects the skin, nervous system, joints and heart [1]. The aetiological agent, Borrelia burgdorferi sensu lato, has been isolated worldwide from various species of ixodid ticks and from human material [2,3]. Initially it was identified as one species. However, because of immunological and molecular heterogeneity $B$. burgdorferi sensu lato has recently been subdivided into

Received 19 Nov. 1998; revised version accepted 28 May 1999.

Corresponding author: Dr Eva Ružić-Sabljić. three pathogenic species: B. afzelii, B. garinii and B. burgdorferi sensu stricto [4]. Whereas strains belonging to the three species have been isolated from European patients with Lyme borreliosis, the only species isolated from patients in the USA has been $B$. burgdorferi sensu stricto.

Genotypic differences have been found to be associated not only with geographical factors but also with the source of material from which borreliae were isolated (man, other mammals or ticks) and with distinct clinical manifestations [5-7]. The major proteins of B. burgdorferi sensu lato have been characterised [8]. Immunoblot studies have shown the predominant antigen determinants to which infected individuals 
respond during the disease [8]. The immune response evoked depends on borrelial protein structure and its antigenic determinants [9], on the duration of infection and its predominant localisation [10] and on host factors.

Lyme borreliosis was first reported in Slovenia in 1985. Since then the number of registered cases has been increasing and various clinical manifestations have been observed. Lyme borreliosis has been found to be endemic, and the most prevalent arthropod-borne infection in Slovenia [11]. B. burgdorferi sensu lato has been cultured from the skin biopsies of patients with erythema migrans (EM) [12], borrelial lymphocytoma [13], acrodermatitis chronica atrophicans (ACA) [6], granuloma annulare [14] and from apparently normal skin at the site of previous EM [15], from cerebrospinal fluid (CSF) [16], synovial fluid, synovia [17] and blood of patients (unpublished data) as well as from I. ricinus ticks [6].

The aim of the present study was to assess the phenotypic and genotypic characteristics of a large number of human isolates of $B$. burgdorferi sensu lato from Slovenia and to identify borrelial species involved in the diverse skin manifestations in patients.

\section{M aterial and methods}

\section{Patients and bacterial strains}

The study analysed 103 isolates of B. burgdorferi sensu lato, obtained during 1991-1997 from the skin, blood and CSF of patients with different skin lesions of Lyme borreliosis: 68 isolates were from patients with solitary $E M$, four from patients with multiple EM, two from skin at the site of previous $E M, 23$ from patients with ACA, four from patients with lymphocytoma and two from patients with non-specific skin lesions; 90 isolates were from skin, eight from blood and five from CSF.

In three patients, borreliae were isolated from two separate specimens: (1) from two different EM lesions in the same patient, (2) from two skin sites in a patient with ACA and (3) from the skin and CSF of a patient with ACA.

Skin biopsy and CSF specimens were inoculated immediately into modified Kelly Pettenkofer (MKP) medium and transported to the laboratory [3]. Citrated blood samples were transported to the laboratory, where they were centrifuged at $800 \mathrm{rpm}$; the supernate was inoculated into MKP medium [3, 14]. All samples were incubated at $33^{\circ} \mathrm{C}$ and examined weekly for the presence of spirochaetes by dark-field microscopy [3].

For the present study, the isolates were grown in MKP medium for 2 weeks at $33^{\circ} \mathrm{C}$ to a cell density of $10^{6} / \mathrm{ml}$. The isolates used in the study had been passaged less than four times.
Protein profiling (SDS-PAGE)

B. burgdorferi sensu lato strains were harvested, washed three times in phosphate-buffered saline with $\mathrm{MgCl}_{2}(\mathrm{PBS} / \mathrm{M} \mathrm{g})$ and resuspended in buffer containing sodium dodecyl sulphate (SDS) $2.5 \%$ and 2-mercaptoethanol 2.5\%. After being boiled for $5 \mathrm{~min}$, samples were electrophoresed through polyacrylamide $12 \%$ gel (PAGE) at $100 \mathrm{~V}$. Gels were stained with Coomassie Brilliant Blue. Low mol. wt marker (BioRad, Münich, Germany) was used as a size marker [8].

\section{DNA isolation}

DNA was prepared by the gel insert method as described previously [18]. Borreliae were washed twice in Tris- $\mathrm{NaCl}$ (TN) buffer, at a concentration of $10^{9} \mathrm{cells} / \mathrm{ml}$, mixed with low gelling temperature agarose $2 \%$ and distributed into the insert moulds. The moulds were incubated at $4^{\circ} \mathrm{C}$ for $30 \mathrm{~min}$ and the solidified agarose inserts were incubated in a lysis solution containing ribonuclease $10 \mu \mathrm{g} / \mathrm{ml}$ and lysozyme $1 \mathrm{mg} / \mathrm{ml}$. The samples were incubated overnight at $37^{\circ} \mathrm{C}$ with gentle shaking. After washing twice in Tris-EDTA (TE) buffer, the inserts were incubated for an additional $72 \mathrm{~h}$ at $50^{\circ} \mathrm{C}$ with gentle shaking in digestion buffer containing proteinase $\mathrm{K} 0.5 \mathrm{mg} / \mathrm{ml}$. The inserts were washed exhaustively with TE buffer and stored at $4^{\circ} \mathrm{C}$ in the same buffer.

Plasmid profiling by pulsed-field gel electrophoresis (PFGE)

Total genomic DNA, including chromosome and plasmids, was analysed by PFGE. The inserts were loaded into wells of agarose $1 \%$ gel. PFGE was performed with the BioRad CHEF-DR III system in 0.5× Tris-borate EDTA (TBE) buffer at $14^{\circ} \mathrm{C}$ with buffer recirculation. The gels were run for $35 \mathrm{~h}$. The initial pulse time was $0.9 \mathrm{~s}$ and the final pulse time was $3.0 \mathrm{~s}$. The mol. wt markers (size 8.3-48.5 kb) were purchased from Sigma and BioRad. Gels were stained with ethidium bromide $0.5 \mu \mathrm{g} / \mathrm{ml}$ and photographed $[15,18]$.

\section{Species identification by PFGE}

The inserts were digested with $30 \mathrm{U}$ of M lul restriction endonuclease overnight at $37^{\circ} \mathrm{C}$ and washed with $\mathrm{TE}$. The DNA fragments obtained after Mlul digestion were separated for $24 \mathrm{~h}$ with varying pulse times of 1$40 \mathrm{~s}$ at a constant voltage of $220 \mathrm{~V}$ (CHEF-DR III, BioRad). The gels were stained with ethidium bromide $0.5 \mu \mathrm{g} / \mathrm{ml}$ and the bands were detected with UV light. L ambda concatamer with monomer size of $48.5 \mathrm{~kb}$ was used as size marker $[15,18]$.

\section{Statistical analysis}

Statistical comparison of qualitative data was performed with Fisher's exact test (two-tailed) or Yates's 
corrected $\chi^{2}$ test with the level of significance set at $\mathrm{p}<0.05$.

\section{R esults}

\section{Species identification}

$B$. afzelii was identified by the presence of specific 440-, 320- and 90-kb bands, B. garinii by the presence of 220 - and $80-\mathrm{kb}$ bands and $\mathrm{B}$. burgdorferi sensu stricto by the presence of a $140-\mathrm{kb}$ band after Mlul digestion [19].

Restriction fragment length polymorphism (RFLP) analysis after Mlul digestion of genomic DNA was performed on all 103 Slovenian isolates and digestion profiles showed that $87(84.5 \%)$ isolates belonged to $B$. afzelii, $15(14.5 \%)$ to $B$. garinii and $1(1 \%)$ to $B$. burgdorferi sensu stricto (Table 1). Fig. 1 shows RFLP of some isolates for all three species. All B. afzelii strains had a unique RFLP pattern, Mlal. B. garinii strains showed heterogeneity within the species: eight strains showed MIg2 RFLP (six from EM patients and two from ACA patients), five had Mlg7 RFLP (three from EM patients and two from ACA patients), one $M$ Ig1 (from an EM patient) and one M Ig4 (EM) RFLP. B. burgdorferi sensu stricto had MIb2 RFLP.

\section{Plasmid analysis}

The plasmid profiles of 53 isolates (40 B. afzelii, 12 B. garinii and 1 B. burgdorferi sensu stricto) were analysed. The number of plasmids in individual strains varied from three to seven and the plasmid size ranged from 15 to $65 \mathrm{~kb}$. Fig. 2 shows the plasmid profiles of some $B$. afzelii strains.

All the isolates except strain E-314 had a large plasmid in the range $49-65 \mathrm{~kb}$ (Fig. 3). Comparison of the large plasmid among the strains showed that the $B$. burgdorferi sensu stricto isolate (E-313) had the smallest plasmid (c. $49 \mathrm{~kb}$ ).

Of 12 B. garinii strains, four strains contained more than one large plasmid in the $49-65 \mathrm{~kb}$ size range: two isolates from the skin of EM (E-21 and E-61) contained three and two isolates from the skin of ACA (E-90 and E-94) contained two large plasmids (Fig. 3). In addition, one B. garinii skin isolate from ACA (E-306), contained a large plasmid dimer of $C$. $100 \mathrm{~kb}$ (Fig. 3).

Of $40 \mathrm{~B}$. afzelii strains, three had plasmid dimers: one ACA skin isolate (E-81) had a single plasmid dimer of C. $100 \mathrm{~kb}$, another ACA skin isolate (E-167) had two copies of a plasmid dimer of 80 and $90 \mathrm{~kb}$, and one CSF isolate from the patient with multiple EM lesions (E-314) had a 100-kb plasmid dimer and lacked large plasmids in the $49-65 \mathrm{~kb}$ size range (Fig. 3).

Comparison of the plasmid profiles of $B$. afzelii and B. garinii isolates showed that the latter more frequently had unusual plasmid contents: 5 of $12 \mathrm{~B}$. garinii and 3 of 40 B. afzelii isolates $(p=0.0115)$. No correlation was found between the possession of unusual plasmid contents and skin manifestations in patients $(p=0.1176)$.

\section{Protein profiling by SDS-PAGE}

The protein profiles of the 103 isolates were examined. The protein composition revealed several major bands that were common to all the strains $(125,100,83,74$, $66,60,41$ and $37 \mathrm{kDa}$ ). Comparison of protein profiles revealed that borreliae possess different protein patterns, especially when comparing low mol. wt proteins OspA, OspB and OspC. Borreliae also showed quantitative differences in the amount of proteins expressed: expression varied from none or very low

Table 1. Results of PFGE of MluI restriction digests of $B$. burgdorferi sensu lato isolates

\begin{tabular}{|c|c|c|c|c|c|}
\hline \multirow[b]{2}{*}{ Source } & \multirow[b]{2}{*}{ Diagnosis } & \multicolumn{4}{|c|}{ Number of isolates identified } \\
\hline & & B. afzelii & B. garinii & $\begin{array}{l}\text { B. burgdorferi } \\
\text { sensu stricto }\end{array}$ & All \\
\hline Skin & $\begin{array}{l}\text { EM (solitary) } \\
\text { EM (multiple) } \\
\text { EM * } \\
\text { ACA } \\
\text { Lymphocytoma } \\
\text { Non-specific } \\
\text { All }\end{array}$ & $\begin{array}{c}51 \\
1 \\
2 \\
16 \\
4 \\
1 \\
75(83.3 \%)\end{array}$ & $\begin{array}{c}9 \\
- \\
- \\
4 \\
- \\
1 \\
14(15.5 \%)\end{array}$ & $\begin{array}{c}- \\
- \\
- \\
1 \\
- \\
- \\
1(1.2 \%)\end{array}$ & $\begin{array}{c}60 \\
1 \\
2 \\
21 \\
4 \\
2 \\
90(100 \%)\end{array}$ \\
\hline CSF & $\begin{array}{l}\text { EM (solitary) } \\
\text { EM (multiple) } \\
\text { ACA } \\
\text { All }\end{array}$ & $\begin{array}{c}1 \\
1 \\
2 \\
4(80 \%)\end{array}$ & $\begin{array}{c}1 \\
- \\
- \\
1(20 \%)\end{array}$ & $\begin{array}{l}- \\
- \\
- \\
-\end{array}$ & $\begin{array}{c}2 \\
1 \\
2 \\
5(100 \%)\end{array}$ \\
\hline Blood & $\begin{array}{ll}\text { EM } & \text { (solitary) } \\
\text { EM } & \text { (multiple) } \\
\text { All } & \end{array}$ & $\begin{array}{c}6 \\
2 \\
8(100 \%) \\
87(84.5 \%)\end{array}$ & $\begin{array}{c}- \\
- \\
- \\
15(14.5 \%)\end{array}$ & $\begin{array}{c}- \\
- \\
- \\
1(1 \%)\end{array}$ & $\begin{array}{c}6 \\
2 \\
8(100 \%) \\
103(100 \%)\end{array}$ \\
\hline
\end{tabular}

EM, erythema migrans; $A C A$, acrodermatitis chronica atrophicans.

*Skin at the site of previous EM. 


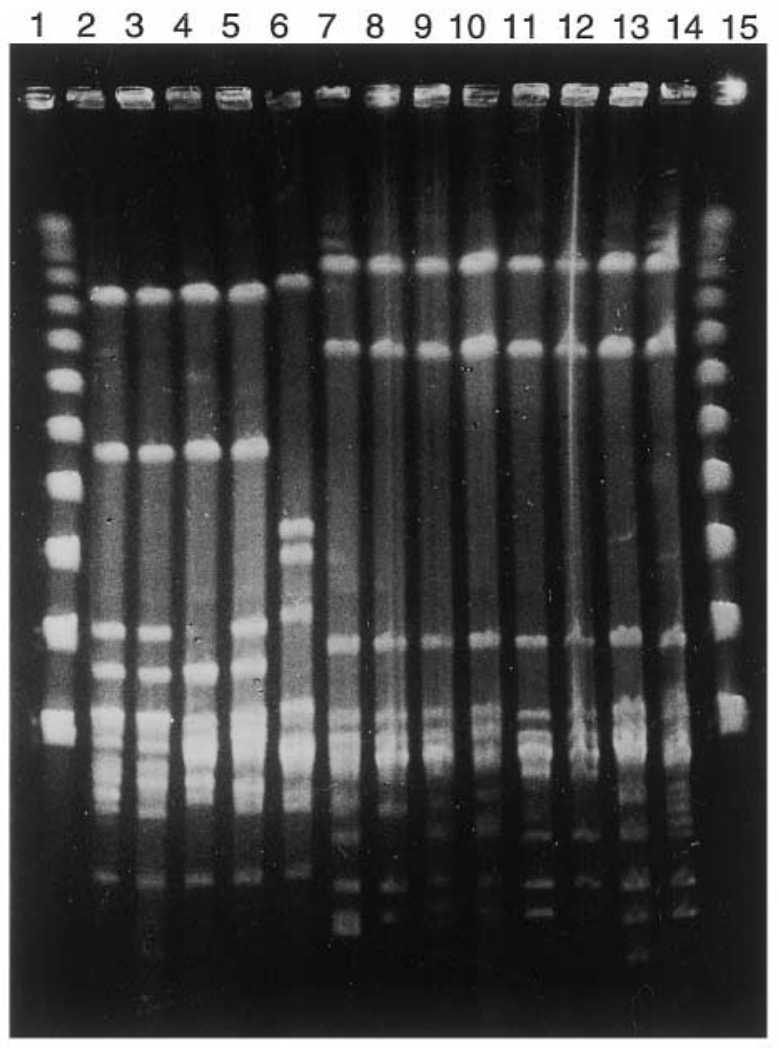

Fig. 1. PFGE of Mlul restriction digests of different $B$. burgdorferi sensu lato isolates. $L$ anes 1 and 15 , molecular size markers (48.5-485 kb; Sigma); 2, 3 and 5, B. garinii Mlg2 isolates; 4, B. garinii MIg4 isolate; 6 , B. burgdorferi sensu stricto Mlb2 isolate; 7-14, B. afzelii Mlal isolates.

to high. Among the proteins, OspC was most frequently highly expressed in the protein profiles. Variations in mol. wt of the same protein among the strains were minimal. Fig. 4 shows the protein profiles of some isolates.

OspA protein was expressed by $98(95.1 \%)$ of $103 \mathrm{~B}$. burgdorferi sensu lato isolates: by $84(96.6 \%)$ B. afzelii isolates and by $13(86.6 \%)$ B. garinii isolates $(p=$ 0.1555). OspB protein was expressed by $82(79.6 \%)$ of 103 B. burgdorferi sensu lato isolates: by $78(89.6 \%)$ B. afzelii isolates and $4(26.6 \%)$ B. garinii isolates. OspC protein was expressed by $66(64 \%)$ of 103 B. burgdorferi sensu lato isolates: by $51(58.6 \%) \mathrm{B}$. afzelii isolates and by $14(93.3 \%) \mathrm{B}$. garinii isolates. When B. afzelii and $B$. garinii isolates were compared, expression of OspB and OspC proteins differed significantly: $B$. afzelii isolates expressed $0 \mathrm{spB}$ more frequently than B. garinii $(p<0.0001)$, while $B$. garinii isolates expressed $\mathrm{OspC}$ more frequently than $B$. afzelii $(p=0.0219)$ (Table 2).

\section{Discussion}

A total of $103 \mathrm{~B}$. burgdorferi sensu lato isolates from patients with different skin manifestations of Lyme borreliosis was analysed (Table 1). Because all were

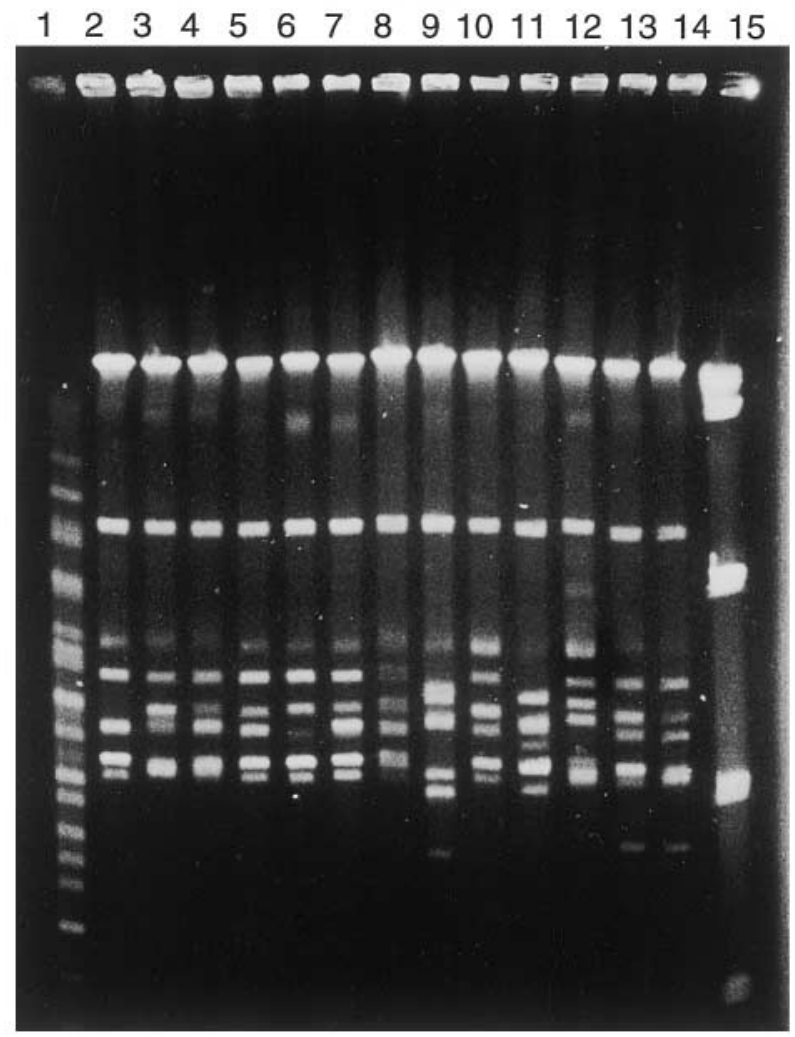

Fig. 2. Plasmid profiles of some B. afzelii isolates determined by PFGE. Lane 1, molecular size markers (8-48 kb; BioRad); 15, molecular size markers (9.4$147 \mathrm{~kb}$; Sigma); 2-4, 9, 11 and 12, skin isolates; 5-8 and 13, blood isolates; 10 and 14, CSF isolates.

low passage isolates (three-to-four subcultures), the influence of in-vitro cultivation referred to by Schwan et al. [20] on their antigen contents would have been limited. Thus, the expression of proteins and definition of species represent authentic in-vivo data from this geographic region, Slovenia, where Lyme borreliosis is endemic $[11,21]$.

PFGE analysis of borrelial genomic DNA proved a suitable approach for characterisation of $B$. burgdorferi sensu lato strains. Furthermore, RFLP was a useful method for the demonstration of genetic homogeneity or heterogeneity of isolates within one species $[6,15]$. All the B. afzelii isolates studied had a unique RFLP (Mla1), whereas species heterogeneity was evident among the B. garinii isolates (Fig. 1). The reason for and the purpose of this heterogeneity have yet to be established.

The present study analysed the DNA of $103 \mathrm{~B}$. burgdorferi sensu lato isolates from the skin, CSF and blood of patients with different skin manifestations of Lyme borreliosis (Table 1). The majority of isolates were found to be B. afzelii (84.5\%), only $14.5 \%$ were B. garinii and $1 \%$ B. burgdorferi sensu stricto. These results corroborate previous findings that $B$. afzelii represents a dominant human skin isolate in Europe as well as in Slovenia $[6,7]$. 


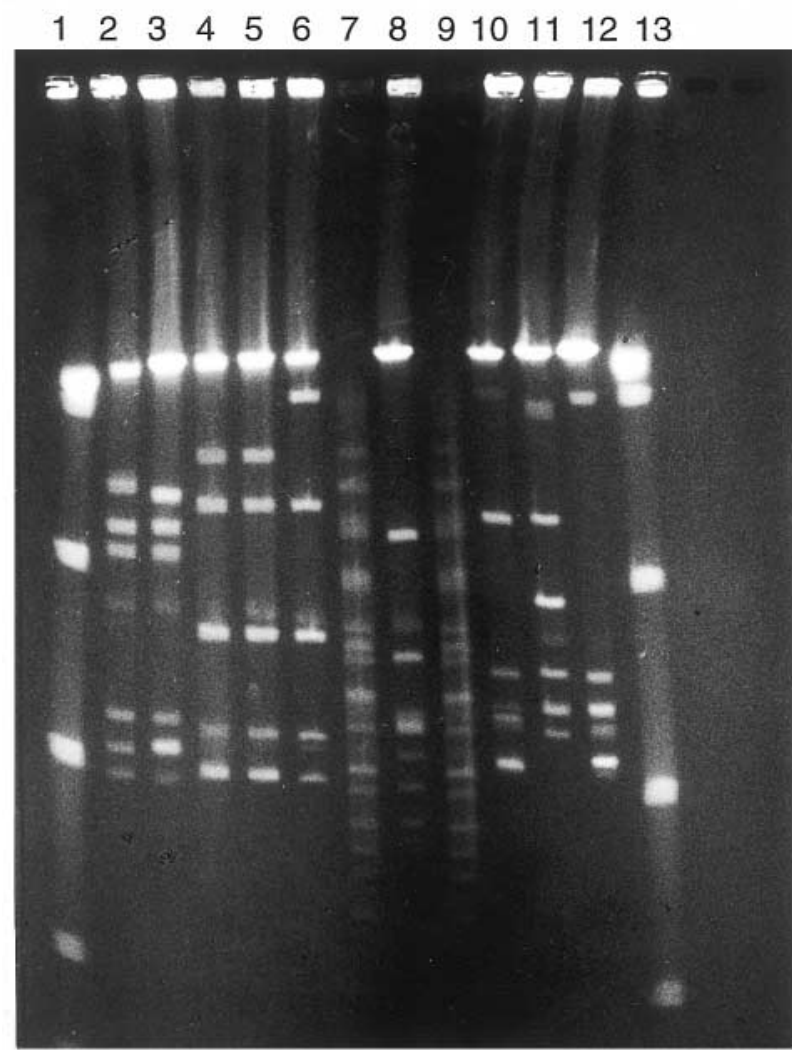

Fig. 3. Plasmid profiles of some B. burgdorferi sensu lato isolates determined by PFGE. Lanes 1 and 13, molecular size markers (9.4-147 kb; Sigma); 7 and 9, molecular size markers (8-48 kb; BioRad); 2-6, B. garinii isolates $(E-21, E-61, E-90, E-94, E-306) ; 8$, B. burgdorferi sensu stricto (E-313); 10-12, B. afzelii isolates (E-81, E-167, E-314).

Only one isolate of $B$. burgdorferi sensu stricto was obtained from the skin of a patient with ACA. The association of $B$. burgdorferi sensu stricto with ACA is rare and has been reported previously in only one patient [22]. In Slovenia B. burgdorferi sensu stricto has been isolated from Ixodes ricinus ticks [23] and from human samples, but very exceptionally $[6,15]$. In addition, the strain designated $M L X$, with phenotypic and genotypic similarities to the unusual North A merican tick isolate 25015, has also been cultured previously from the skin and CSF of Slovenian patients with Lyme borreliosis, but was not found in the present study [24].

Plasmids represent a significant part of the genetic capacity of Borrelia spp. They are very useful for strain differentiation, especially differentiation within the species. Strains with multiple large plasmids or plasmid dimers are rare; they have been found in $B$. garinii, B. afzelii and B. japonica, $[25,26]$. In the present study, multiple large plasmids were found among the $B$. garinii isolates (4 of 12), and plasmid dimers in 3 of 40 B. afzelii and 1 of 12 B. garinii isolates. Unusual plasmid profiles were found more often among the $B$. garinii than the $B$. afzelii isolates $(p=0.0115)$. The presence of phenotypic differences in these strains was anticipated. However, an unusual plasmid profile did not appear to correlate with protein profiles. It seems that the expression of Osp is not dependent on the plasmid contents; it must be controlled and regulated by other mechanisms. It is interesting to note that strains with unusual plasmid contents were isolated more often from patients with chronic Lyme borreliosis (5 of 16 ACA) than from patients with early infection ( 3 of $30 \mathrm{EM}$ ), but it was not of statistical significance $(p=0.1176)$. It remains to be elucidated whether these plasmids are responsible for the chronicity of the infection or are the result of long-lasting borrelial infection, or whether the finding is coincidental.

\section{$\begin{array}{llllllll}1 & 2 & 3 & 4 & 5 & 6 & 7 & 8\end{array}$}

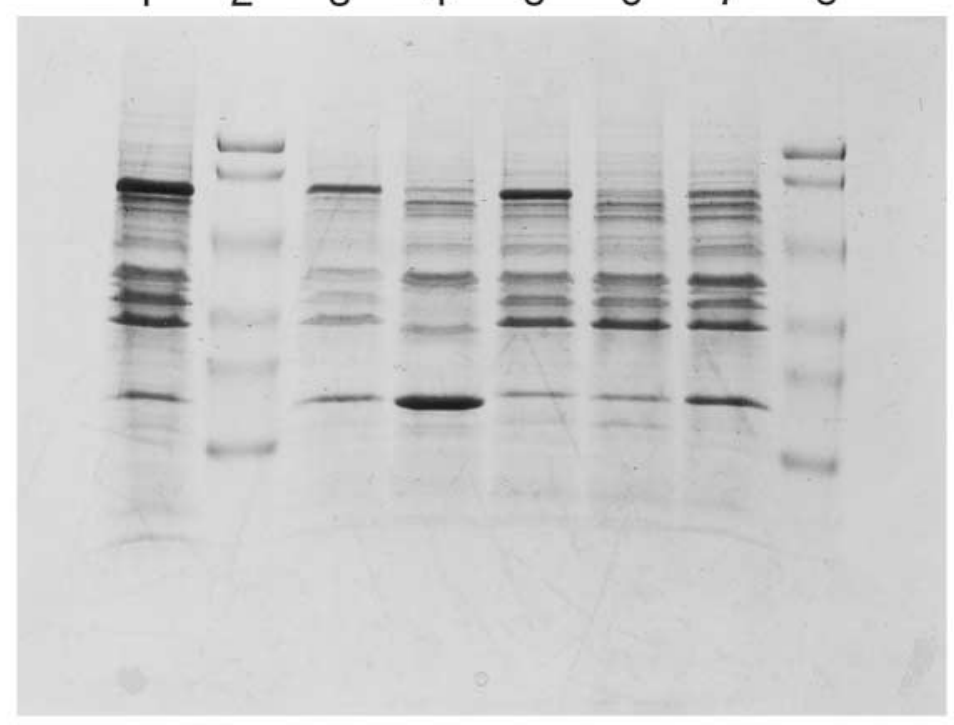

Fig. 4. Coomassie Blue-stained SDS-PAGE of whole cell proteins. Lanes 2 and 8, molecular size markers (16-110 kDa; BioRad); 1 and 3-7, B. burgdorferi sensu lato isolates. 
Table 2. Low mol.wt protein expression by B. afzelii, $B$. garinii and B. burgdorferi sensu stricto isolates from patients with skin manifestations of Lyme borreliosis in Slovenia

\begin{tabular}{lrrrr}
\hline & \multicolumn{4}{c}{ Number (\%) of isolates that expressed Osps } \\
\cline { 2 - 5 } Species & \multicolumn{1}{c}{ OspA } & \multicolumn{1}{c}{ OspB } & OspC & A ny Osp \\
\hline B. afzelii & $84(96.6)$ & $78(89.6)$ & $51(58.6)$ & $87(100)$ \\
B. garinii & $13(86.6)$ & $4(26.6)$ & $14(93.3)$ & $15(100)$ \\
B. burgdorferi & $1(100)$ & - & $1(100)$ & $1(100)$ \\
sensu stricto & $98(95.1)$ & $82(79.6)$ & $66(64)$ & $103(100)$ \\
All & & & &
\end{tabular}

The protein component of $B$. burgdorferi sensu lato is known to vary among natural isolates; moreover, differences are also found within the clones of a single isolate, particularly regarding $\mathrm{OspA}, \mathrm{OspB}$ and $\mathrm{OspC}$, which are specific proteins for $B$. burgdorferi sensu lato [8]. Slovenian strains also demonstrated protein diversity ranging from non-expression to high expression of an individual Osp. OspA was expressed by $95.1 \%, 0$ spB by $79.6 \%$ and 0 spC by $64 \%$ of isolates in the present study. The findings with regard to $\mathrm{OspC}$ expression are of interest because they are in contrast not only with North A merican findings but also with some European reports. It has been reported that $0 \mathrm{spC}$ protein was expressed by $45 \%$ of European isolates and was rarely seen in North A merican isolates $[27,28]$. However, OspC protein was found quite frequently among North A merican isolates from ticks and other animals, but rarely in large amounts [29]. As reported previously by Wilske et al. [8], heterogeneity of the borrelial proteins could also be demonstrated by the variation in mol. wt of the same individual protein among different strains. However, it should be stressed that variations in the mol. wt of borrelial proteins in the present study were minimal. Some isolates examined in the present study showed a negative correlation between the amount of $\mathrm{OspC}$ on one hand, and OspA or OspB, or both, on the other (Fig. 4).

Statistical analysis of protein profiles of 103 Slovenian isolates identified at the species level (Table 2 ) revealed a higher expression rate of $\mathrm{OspB}$ among $\mathrm{B}$. afzelii than among $B$. garinii isolates $(p<0.0001)$ and a higher expression rate of $\mathrm{OspC}$ among $\mathrm{B}$. garinii than among $B$. afzelii isolates $(p=0.0219)$. No significant difference in the expression of OspA protein was found between the $B$. afzelii and $B$. garinii isolates. The exact role of $\mathrm{Osp}$, especially $\mathrm{OspB}$ and $\mathrm{OspC}$, for virulence and the pathogenesis of Lyme borreliosis remains to be determined.

When interpreting the genotype spectrum of $B$. burgdorferi sensu lato isolates from certain regions it is important to recognise that it may be influenced by regional dissimilarities, by the biological source of the isolates (human, ticks), and by clinical manifestations or the tissue from which borreliae are isolated [6]. Differences in antibiotic susceptibility between the species as well as within one species have also been reported by Preac-Mursic et al. [17]. All the isolates described in the present study were obtained from human patients with Lyme borreliosis, who lived in a relatively small, well-defined geographical region. In Slovenia, B. afzelii is the most prevalent causative agent of Lyme borreliosis and EM is the most frequent clinical manifestation of the infection.

Several studies have shown an association of B. afzelii with skin manifestations and B. garinii with neuroborreliosis [7]. The Osp of these strains may be important for the infection of different organ systems.

In the course of infection, patients' antibodies are directed against antigens that are expressed by the particular strain causing the infection. Comparison of the antibody response to autologous and heterologous isolates in patients with Lyme borreliosis showed a tendency towards a stronger response to autologous isolates [9]. A ntigen-dependent differences in serological tests have also been demonstrated [10]. These findings indicate that the choice of a $\mathrm{B}$. burgdorferi sensu lato strain for an antigen in serological testing is important.

Knowledge of differences in immunodominant proteins in different geographical areas is also an important consideration as regards vaccine development. In an endemic region, such as Slovenia, where different genotypic strains are associated with the disease, it is important to analyse the antigenic structure of Borrelia spp. to find the best antigen combination for serological tests, and for the development of an appropriate vaccine.

The isolation of $\mathrm{B}$. burgdorferi sensu lato from different clinical manifestations of Lyme borreliosis, as shown in the present study, confirms the broad spectrum of clinical manifestations that infection can cause. Furthermore, the isolation of B. burgdorferi sensu lato from the blood of patients with EM (Table 1) should alert clinicians to the fact that borreliae can probably disseminate early in the infection almost without any generalised clinical signs (in the patients investigated in the present study, the duration of EM was 1-39 days, median value 6 days). Isolation of B. burgdorferi sensu lato from the CSF confirms that neurological manifestations can appear during EM. In additon to isolates from skin, blood and CSF of patients with EM, Borrelia spp. were also isolated from the skin and CSF of two patients with $A C A$, which confirms that ACA is a chronic, systemic borrelial infection. It is interesting that in spite of the high antibody levels found in patients with ACA, borreliae can persist in different organ systems. These isolates were examined carefully; their antigens did not differ from those of other isolates. However, an unusual plasmid content was found more frequently in strains isolated from long-lasting skin lesions than from EM. 
In conclusion, these results demonstrate a heterogeneity of plasmid profiles and Osp protein expression in 103 isolates from patients with skin manifestations of Lyme borreliosis. All three species of $\mathrm{B}$. burgdorferi were isolated from skin biopsies. Furthermore, B. garinii was detected in the CSF of patients with EM, B. afzelii in the CSF of patients with EM and ACA, as well as B. burgdorferi sensu stricto from the skin of a patient with ACA.

\section{R eferences}

1. Steere AC. Lyme disease. N Engl J Med 1989; 321: 586- 596.

2. Nadelman RR, Pavia CS, Magnarelli LA, Wormser GP. Isolation of Borrelia burgdorferi from the blood of seven patients with Lyme disease. Am J Med 1990; 88: 21-26.

3. Preac-Mursic V, Wilske B, Schierz G. European Borrelia burgdorferi isolated from humans and ticks. Culture conditions and antibiotic susceptibility. Zentralbl Bakteriol Mikrobiol Hyg A 1986; 263: 112-118.

4. Baranton G, Postic D, Saint-Girons I et al. Delineation of Borrelia burgdorferi sensu stricto, Borrelia garinii sp.nov., and group VS461 associated with Lyme borreliosis. Int J Syst Bacteriol 1992; 42: 378-383.

5. A dam T, Gassmann GS, Rasiah C, Göbel UB. Phenotypic and genotypic analysis of Borrelia burgdorferi isolates from various sources. Infect Immun 1991; 59: 2579- 2585.

6. Picken RN, Cheng $Y$, Strle $F$ et al. M olecular characterization of Borrelia burgdorferi sensu lato from Slovenia revealing significant differences between tick and human isolates. Eur j Clin Microbiol Infect Dis 1996; 15: 313-323.

7. van Dam AP, Kuiper $H$, Vos $K$ et al. Different genospecies of Borrelia burgdorferi are associated with distinct clinical manifestations of Lyme borreliosis. Clin Infect Dis 1993; 17: 708-717.

8. Wilske B, Preac-Mursic V, Schierz G, Kühbeck $R$, Barbour $A G, K$ ramer $M$. Antigenic variability of Borrelia burgdorferi. Ann NY Acad Sci 1988; 539: 126-143.

9. Karlsson M. Antibody response against autologous and heterologous isolates of Borrelia burgdorferi in four patients with Lyme neuroborreliosis. Eur J Clin Microbiol Infect Dis 1991; 10: 742-745.

10. Wilske B, Preac-Mursic V, A shierz G, Liegl G, Gueye W. Detection of $\mathrm{IgM}$ and $\mathrm{IgG}$ antibodies to Borrelia burgdorferi using different strains as antigen. In: Stanek $G$ (ed) Lyme borreliosis II. Stuttgart, Gustav Fischer. 1989: 299-309.

11. Strle F, Maraspin-Carman V, Furlan-Lotric S, Ružić-Sabljić E, Pletrski-Rigler D, Cimperman J. Epidemiological features of Lyme borreliosis in Slovenia. Zdrav Vestn 1995; 64: 145- 150.

12. Strle $F, N$ elson JA, Ružić-Sabljić $E$ et al. European Lyme borreliosis: 231 culture-confirmed cases involving patients with erythema migrans. Clin Infect Dis 1996; 23: 61-65.

13. Picken RN, Strle F, Ružić-Sabljić E et al. Molecular subtyping of Borrelia burgdorferi sensu lato isolates from five patients with solitary lymphocytoma. J Invest Dermatol 1997; 108: 92- 97.

14. Strle F, Preac-Mursic V, Ružić E, Wilske B, Cimperman J.
Isolation of Borrelia burgdorferi from a skin lesion in a patient with granuloma annulare. Infection 1991; 19: 351-352.

15. Strle F, Cheng $Y$, Cimperman J et al. Persistence of Borrelia burgdorferi sensu lato in resolved erythema migrans lesions. Clin Infect Dis 1995; 21: 380-389.

16. Strle F, Ružić E, Cimperman J, M araspin V, Lotric S. Isolation of Borrelia burgdorferi from normal cerebrospinal fluid in seronegative patients with erythema migrans and peripheral facial palsy. Ann Rheum Dis 1993; 52: 411.

17. Preac-M ursic V, Marget W, Busch U, Pleterski-Rigler D, Hagl S. Kill kinetics of Borrelia burgdorferi and bacterial findings in relation to the treatment of Lyme borreliosis. Infection 1996; 24: 9-16.

18. Busch U, Hizo-Teufel C, Boehmer R, Wilske B, Preac-M ursic V. Molecular characterization of Borrelia burgdorferi sensu lato strains by pulsed-field gel electrophoresis. Electrophoresis 1995; 16: 744-747.

19. Belfaiza J, Postic D, Bellenger $E, B$ aranton $G$, Saint Girons I. Genomic fingerprinting of Borrelia burgdorferi sensu lato by pulsed-field electrophoresis. J Clin Microbiol 1993; 31: 2873- 2877.

20. Schwan TG, Burgdorfer W. Antigenic changes of Borrelia burgdorferi as a result of in vitro cultivation. J Infect Dis 1987; 156: 852-853.

21. Strle F, Stantic-Pavlinić M. Lyme disease in Europe. N Engl J Med 1996; 334: 803.

22. Picken RN, Strle $F$, Picken $M M$ et al. Identification of three species of Borrelia burgdorferi sensu lato (B. burgdorferi sensu stricto, B. garini, and B. afzelii) among isolates from acrodermatitis chronica atrophicans lesions. J Invest Dermatol 1998; 110: 211-214.

23. Strle $F$, Cheng $Y$, Nelson JA, Picken MM, Bouseman JK, Picken RN. Infection rate of Ixodes ricinus ticks with Borrelia afzelii, Borrelia garinii, and Borrelia burgdorferi sensu stricto in Slovenia. Eur J Clin Microbiol Infect Dis 1995; 14: 994- 1001

24. Picken RN, Cheng $Y$, Strle F, Picken M M. Patient isolates of Borrelia burgdorferi sensu lato with genotypic and phenotypic similarities to strain 25015. J Infect Dis 1996; 174: $1112-1115$

25. Marconi RT, Casjens S, Munderloh UG, Samuels DS A nalysis of linear plasmid dimers in Borrelia burgdorferi sensu lato isolates: implications concerning the potential mechanism of linear plasmid replication. I Bacteriol 1996; 178: 3357-3361.

26. $X u Y$, Johnson RC. Analysis and comparison of plasmid profiles of Borrelia burgdoferi sensu lato strains. J Clin Microbiol 1995; 33: 2679-2685.

27. Kurashige $S$, Bissett $M$, Oshiro $L$. Characterization of a tick isolate of Borrelia burgdorferi that possesses a major lowmolecular-weight surface protein. J Clin Microbiol 1990; 28: $1362-1366$.

28. Wilske $B$, Preac-Mursic $V$, Fuchs $R$ et al. Immunodominant proteins of Borrelia burgdorferi: implications for improving serodiagnosis of Lyme borreliosis. In: $\mathrm{Neu} \mathrm{HC}$ (ed) $\mathrm{New}$ antibacterial strategies. (Frontiers in infectious diseases ser.) Edinburgh, Churchill Livingstone. 1990: 47-63.

29. Picken RN, Cheng Y, Han D et al. Genotypic and phenotypic characterization of Borrelia burgdorferi isolated from ticks and small animals in Illinois. I Clin Microbiol 1995; 33: 2304- 2315. 